\title{
Social Impact of Broadband Internet: A Case Study in the Shippagan Area, a Rural Zone in Atlantic Canada
}

\author{
Sid-Ahmed Selouani \\ Université de Moncton, \\ Shippagan, Canada
}

\author{
Habib Hamam \\ Université de Moncton, \\ Moncton, Canada
}

hamamh@umoncton.ca

\begin{abstract}
This paper provides evidence of social transformations induced by the high-speed, always on, Internet connectivity (broadband) in the Acadian Peninsula of New Brunswick with a focus on the town of Shippagan and its parish. We outline examples of transformations on rural communities and summarize important barriers to their effective use of broadband. The major finding of our case study research is that there are many examples of new uses and activities because of adoption of broadband, in spite of the fact that broadband technology has very recently been introduced in the Acadian Peninsula. We have also noticed that there are few cases of changes in behaviours, attitudes, relationships, and operating norms, as a result.
\end{abstract}

Keywords: Broadband Internet, social impact, rural region, Atlantic Canada

\section{Introduction}

According to the latest OECD (Organisation for Economic Co-Operation and Development) broadband statistics, Canadians are among the world's leaders in the use of broadband. We define broadband as high-speed, always on, Internet connectivity, with a minimum of $1.5 \mathrm{Mbps}$ of data transfer permitting the transfer of large files, especially video files. Around $22.4 \%$ of all regular home Internet use households had a high-speed Internet connection in June 2006 (Organisation for Economic Co-Operation and Development [OECD], 2006). This proportion increased from East to West, with $61 \%$ of regular home Internet-use households connecting using broadband in British Columbia on the West coast, compared to $39 \%$ in the Atlantic Provinces at the East coast. The Information and Cultural Industries continued to be leaders in broadband penetration (86\%). Analysis by enterprise size revealed that broadband use was higher among large firms (Veenhof, Neogi, \& Van Tol, 2003).

However, the gradient of broadband penetration in Canada is low especially with respect to that

Material published as part of this publication, either on-line or in print, is copyrighted by the Informing Science Institute. Permission to make digital or paper copy of part or all of these works for personal or classroom use is granted without fee provided that the copies are not made or distributed for profit or commercial advantage AND that copies 1) bear this notice in full and 2) give the full citation on the first page. It is permissible to abstract these works so long as credit is given. To copy in all other cases or to republish or to post on a server or to redistribute to lists requires specific permission and payment of a fee. Contact Publisher@InformingScience.org to request redistribution permission. of the USA. In fact, according to the April 2006 Bandwidth report ("US Broadband", 2006), over the past year, the broadband gap between Canada and the US has narrowed from 20 percentage points to 6.6 percentage points. Since last March, US broadband penetration rose 12.4 percentage points while Canadian broadband penetration was flat. Canada is still ahead, but the gap is 
closing. In the world, Denmark is still in the lead when comparing the ratio of broadband subscribers to inhabitants. Out of every hundred Danes, 29 have a broadband connection. That compares to 19 in the USA and 22 in Canada (Fransman, 2006; OECD, 2006).

It is obvious that the Internet, in general, and broadband technology, in particular, is affecting Canadian social life. As stated by Public Works and Government Services Canada, adult Canadians are spending time online. According to the Canada Demographic Profile Report published in October 2004, the 14.5 million Canadian Internet users over the age of 18 each spend an average of 37 hours online per month (Comscore Media Metrix, 2004; Zamaria, Caron, \& Fletcher, 2005). In the present work, we attempt to identify some social impacts of broadband use in a rural zone of the Acadian Peninsula, namely the town of Shippagan and its parish.

The following are definitions of the key concepts in our study.

Broadband provides access to on-line information and services that are essential for governments, businesses, and the public to operate effectively in the information age. The main technical principles behind the major fixed line broadband technologies are as follows: ADSL (Asymmetrical Digital Subscriber Line), VDSL (Very High Rate Digital Subscriber Line, also known as Fiber to the Node or Curb - FttN/FttC), Fiber to the Premises or the Home (FttP/FttH), Hybrid Fiber Coax (HFC) Cable and Broadband over Power lines (BPL) (Corning Inc., 2005).

We define community as a cluster of communities (municipal and non-incorporated) which have a common economic (and to a certain extent, social and cultural as well) affiliation with each other. The Census Consolidated Subdivision geography used by Statistics Canada was employed for identifying these communities across the province (Statistics Canada, 2006).

Rural New Brunswick is defined as the geography of the province covered by the 12 rural Enterprise Agencies (see Figure 1). There are 15 such agencies, but three of them serve the Fredericton, Moncton, and Saint John urban centres. The Province of New Brunswick uses this urbanrural delineation to organize a variety of its public service and program delivery activities. We are concerned with the Shippagan area (the rural zone filled in gray in Figure 1). The term transformation is used to refer to a system-wide change in behaviours, practices, processes, and relationships.

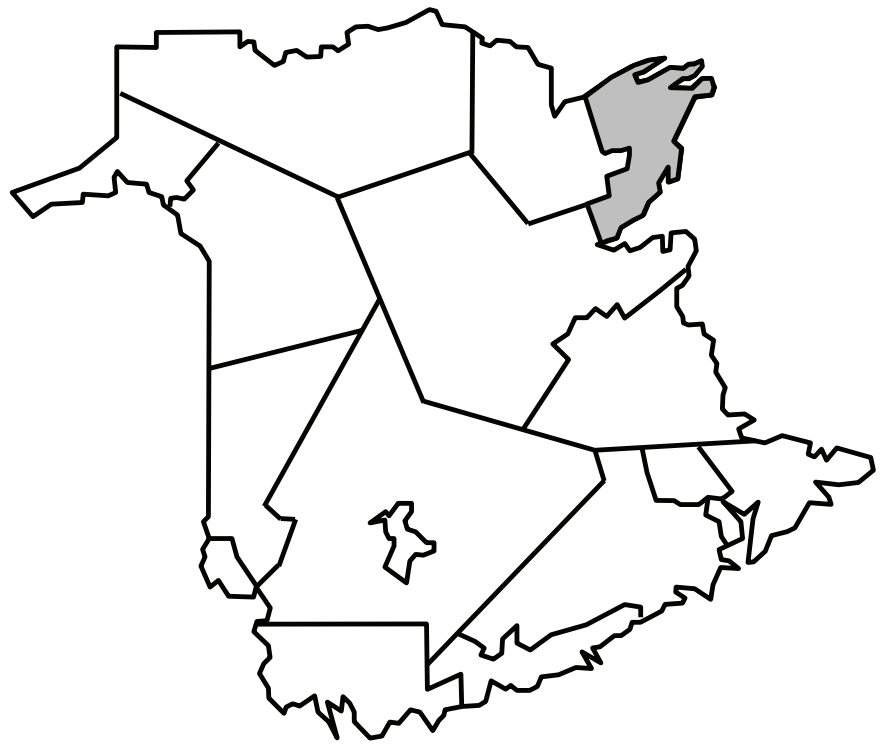

Figure 1: The 12 New Brunswick rural areas. Shippagan area is in gray. 


\section{Purpose and Context of the Study}

In 1997 it was estimated that New Brunswick matched the national average for Internet adopters, but it has since slipped considerably over the past 8 years (New Brunswick Universities Broadband Research Consortium [NBUBRC], 2006; Selouani, Hamam, \& Benahmed, 2007). Through the initiative of Infrastructure Canada and jointly with the Province of New Brunswick and Aliant (CSIP-NB), the three partners announced the $\$ 44.6 \mathrm{M}$ broadband infrastructure program for New Brunswick on November 18, 2003. Their purpose was as follows:

- to enable government to better design programs and to inform policymaking related to broadband;

- to help communities to measure and improve the benefits they are receiving from broadband.

Their goal was as follows:

- to determine the economic and social impacts of broadband infrastructure on and in rural communities in New Brunswick;

- to measure the specific results for rural, aboriginal, and official language minority (OLM).

Through the CSIP-NB project, broadband would be made accessible to an additional 327 communities located in 12 rural regions of the Province, specifically: 106800 residences (90\%), 24240 businesses (95\%), 130 schools (98\%), all 29 healthcare centers (100\%), 16 business parks (100\%), all 13 First Nations communities (100\%) (NBUBRC, 2006; Selouani et al., 2007).

Furthermore, a research project originated as a result of discussions among a variety of federal, provincial, non-governmental, and private sector partners and stakeholders, all interested in understanding the economic, social, institutional, and community impacts of broadband adoption and use in rural New Brunswick. The university research community in New Brunswick was invited to collaborate on a long term, longitudinal, multi-disciplinary research project to assess these impacts. The authors were concerned with the Shippagan rural area. In March 2006, the NB Universities Broadband Research Consortium completed a preliminary study of broadband adoption, use, and impacts in rural New Brunswick. In April 2006, the consortium authorized its members to diffuse the results concerning their case studies. Given that business aspects go beyond the scope of the present paper, it will be the subject of a future separate publication.

The purpose of the study, mainly financed by Industry Canada, is to advance our understanding of the current state of broadband use in rural New Brunswick. The main objectives in conducting our research with respect to social aspects were:

- to identify and measure (where possible) the social transformational changes that can be attributed to the uptake of broadband technologies within communities;

- to increase Canadian research capacity and expertise in the area of measuring impacts of broadband infrastructure in communities;

- to develop a body of knowledge which will guide and support future policy and program decisions and directions;

- to develop accessible, relevant, and useful research results for the communities as well as other key stakeholders. 
The study investigated the Shippagan area, located on the North-eastern side of the Acadian Peninsula, in North-eastern New Brunswick. Shippagan is known as the commercial fishing capital of New Brunswick. Shippagan and Lamèque are two of the three major ports of the Acadian Peninsula. Le Goulet and Ste- Marie- St Raphael are the two main villages in the neighbourhood of Shippagan and Lamèque respectively (see Figure 2). To access the island of Lamèque and $\mathrm{St}$ Marie-St Raphael village you have to go through the town of Shippagan and across its drawbridge.

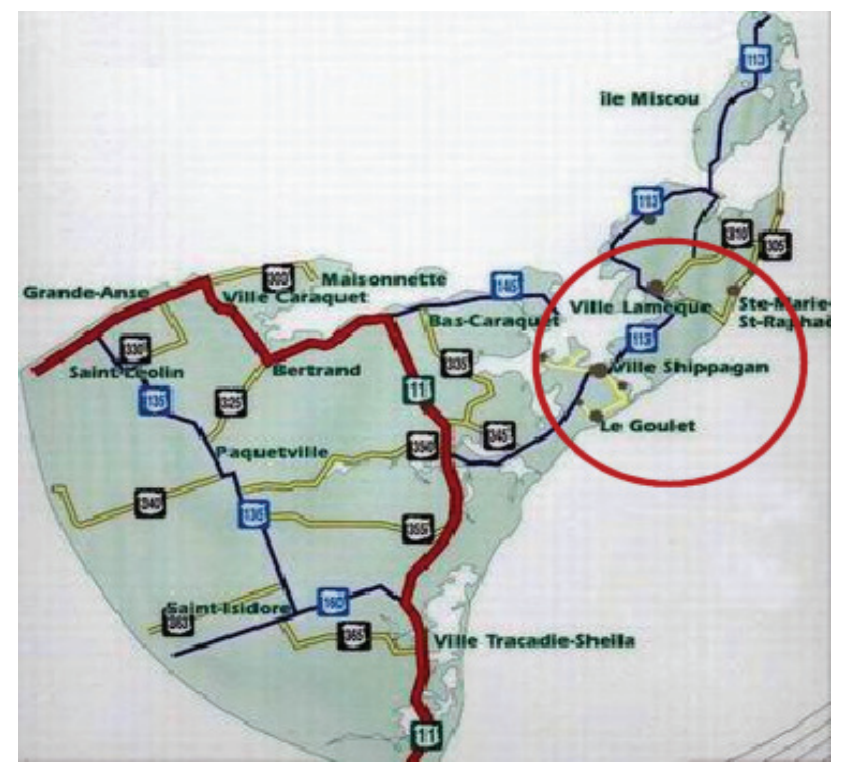

Figure 2: The Acadian Peninsula. The main Shippagan region is encircled.

The total population of the regions concerned in this case study is 7691, which, compared to the 1996 census, shows a reduction of $4.2 \%$. The average of this diminution in New Brunswick is $1.2 \%$. Table 1 gives the distribution of the population in these regions according to the 2001 census.

There is a sign of an obvious demographic ageing; young people of less than 15 years, constitute $16.3 \%$ of the population, compared to $17.8 \%$ for New Brunswick and $19.1 \%$ for Canada.

People of intermediate age (30-64 years) are relatively numerous. This group, by far the most active within the populations, and is composed of $51 \%$ of the total population, compared to $49 \%$ for New Brunswick and $48.3 \%$ for Canada. Table 2 gives the median age and the percentage of the population aged 15 and over.

Table 1: Distribution of the population in the case study regions (Statistics Canada, 2001)

\begin{tabular}{|l|l|l|c|c|}
\hline Locality & Shippagan & Lamèque & Le Goulet & Ste-Marie \\
\hline Population & 2872 & 1580 & 969 & 1135 \\
\hline
\end{tabular}


Table 2: Age distribution in the case study regions (Statistics Canada, 2001)

\begin{tabular}{|l|c|c|c|c|}
\multicolumn{1}{|c|}{ Locality } & Shippagan & Lamèque & Le Goulet & Ste-Marie \\
\hline Median age & 39.9 & 39.7 & 39.9 & 39.6 \\
\hline \% of the population ages 15 and over & 84.2 & 84.8 & 86.6 & 84.6 \\
\hline
\end{tabular}

While French is the native language of the vast majority of the inhabitants, nearly $50 \%$ of people speak both French and English. Nearly 34\% of the active population complete their secondary level studies; $44 \%$ complete their postsecondary studies. The most important demographic data of the population of New Brunswick for our study are summarized in Table 3.

Table 3: Population of the New Brunswick and Shippagan area

\begin{tabular}{lll} 
Census Statistics & New Brunswick & Shippagan Case Study Area \\
2001 Population & $\mathbf{7 2 9 , 4 9 8}$ & $\mathbf{1 2 , 1 5 6}$ \\
1996-2001 Population Change & $-1.2 \%$ & $-4.0 \%$ \\
\hline Private Dwellings & 313,609 & 5,035 \\
\hline Age Distribution & & 12,160 \\
$0-85+$ (actual) & 729,495 & $1,840(15 \%)$ \\
$0-14$ & $130,100(18 \%)$ & $1,645(14 \%)$ \\
$15-24$ & $97,435(13 \%)$ & $3,780(31 \%)$ \\
$25-44$ & $216,975(30 \%)$ & $3,355(28 \%)$ \\
$45-64$ & $186,065(26 \%)$ & $1,510(12 \%)$ \\
\hline $65+$ & $98,935(14 \%)$ & $\mathbf{2 , 3 5 0}$ \\
\hline Education Attainment (Popula- & $\mathbf{1 4 0 , 7 2 0}$ & $29.6 \%$ \\
tion Age 20-34) & $17.0 \%$ & $15.1 \%$ \\
Did not complete High School & $18.0 \%$ & 9,330 \\
\hline Completed University Degree & 2,070 \\
\hline Mobility status - place of residence 5 years ago & 458,415 & \\
Same address & 223,355 & \\
\hline Completed University Degree & \\
\hline
\end{tabular}

Note: Source: Statistics Canada, 2001 Population Census.

Broadband access arrived in the Shippagan area at different times. The town of Shippagan was the first to receive access in the spring of 2000, with some surrounding areas receiving it shortly thereafter. Further expansion was done in late 2005, and early 2006 (see Table 4). 
Table 4: Broadband penetration in Shippagan communities

(Data were graciously provided by Bell-Aliant: http://www.aliant.ca )

\begin{tabular}{|c|c|c|c|c|c|}
\hline \multicolumn{6}{|c|}{ Broadband Penetration Rate } \\
\hline \multirow[t]{2}{*}{ Community } & Homes & & & Custumer Base: & $\%$ of Penetration \\
\hline & Passed & Launched & Service & 8-Mar-06 & \\
\hline Shippagan & 2,038 & Apr 1, 2000 & 5.9 & 638 & $31 \%$ \\
\hline $\begin{array}{l}\text { Miscou Centre } \\
\text { (Shippagan) }\end{array}$ & 0 & Planned & 0.0 & 0 & $\mathrm{n} / \mathrm{a}$ \\
\hline $\begin{array}{l}\text { Saint-Cecile } \\
\text { (Shippagan) }\end{array}$ & 297 & Dec 12, 2005 & 0.3 & 59 & $20 \%$ \\
\hline $\begin{array}{l}\text { Petit Lamèque } \\
\text { (Shippagan) }\end{array}$ & 262 & Jan 9, 2006 & 0.2 & 61 & $23 \%$ \\
\hline $\begin{array}{l}\text { Pigeon Hill } \\
\text { (Shippagan) }\end{array}$ & 371 & Jul 5, 2005 & 0.7 & 122 & $33 \%$ \\
\hline Lamèque & 1,708 & Jun 2, 2000 & 5.7 & 311 & $18 \%$ \\
\hline $\begin{array}{l}\text { St-Marie-St } \\
\text { Raphael }\end{array}$ & 420 & Jul 4, 2005 & 0.7 & 110 & $26 \%$ \\
\hline (Lamèque) & & & & & \\
\hline $\begin{array}{l}\text { Le Goulet } \\
\text { (Lamèque) }\end{array}$ & 353 & Jan 6, 2006 & 0.2 & 105 & $30 \%$ \\
\hline$\overline{\text { Shippagan Tots }}$ & 5,449 & & & 1,406 & $26 \%$ \\
\hline
\end{tabular}

\section{Literature Review}

Early studies on impacts of broadband computer networks on society mainly focus on offering expert opinions, forecasting future trends, and speculating about the potential of the technology. More recent studies attempted to assess the penetration rate of broadband by focusing on specific types of applications requiring high speed (Chang, Lee, \& Middleton, 2004; Cohill, 2005a, 2005b; Lee, O'Keefe, \& Yun, 2003). These studies also attempted to quantify the subscriber volume, which stands for the number and percent of customers purchasing the service. The studies have typically covered the "private sector business case" for broadband deployment and investments (Chang et al., 2004; Cohill, 2005a, 2005b; Lee et al., 2003). This has been especially the case in the United States where there is little public investment in the technology (NBUBRC, 2006).

Other studies went further in studying the business case by attempting to provide quantitative elements on either the return on investment in broadband infrastructure or the economic outcomes of subscribing to or using broadband technology. In other words, these studies attempted to assess either how much economic activity and further investment can be attributed to broadband expenses or how much savings have been achieved, how many jobs have been created, and so on. These attempts have faced challenges with data collection. Another major challenge was the issue of isolating the quantifiable impacts or changes that can be assigned specifically to broadband usage from those which are caused by other factors (Marlin \& Bruce, 2006; NBUBRC, 2006).

Ruiz (2004) found that broadband access is an important part of enhancing rural community development in the United States, improving the economy, health care, and general quality of life.

A series of economic impact case studies have been conducted by the Strategic Networks Group (SNG projects) and their various partners across a number of rural communities and regions in 
Canada. Ruiz (2004) reported that the effects on the lives of rural Americans of limited telecommunication and information technologies, specifically the broadband Internet, has required the attention of economists, researchers, and government officials such as the Federal Communications Commission (FCC). The report pointed out that rural areas cannot remain economically or culturally viable without the high-speed connection of broadband Internet. Indeed, without having the same telecommunications facilities, such as broadband, afforded to other parts of the world, rural communities suffer from inadequate social services, weakened businesses, and a deficient quality of life (Ruiz, 2004). One of the consequences of lack of those facilities is that young people move away from their smaller childhood towns to urban places that offer more opportunity (Platis, 2004). Moreover, small-town businesses cannot compete with urban businesses, and social programs, such as health and education, are negatively affected in rural communities (Bush, 2004) without technologies such as broadband Internet. Ruiz (2004) emphasized that many rural areas literally become ghost towns as people move to areas that offer greater work opportunities and education that take advantage of broadband technology. Because the increasing economic and cultural isolation of rural communities presents a social problem, the question of how to ensure that these areas have access to the broadband Internet begs an answer from the government (Ruiz, 2004).

In other case studies (Strategic Networks Group (SNG), EKOS, \& Phoenix Strategic Perspectives, 2004), the monetary volume of investments in broadband technology were applied across a complex group of industries and then modelled for their direct and indirect economic value through a series of simulations against local, regional, and external economies (NBUBRC, 2006). The aim was to determine the economic drivers and gaps within the community and create a basis for a future economic growth strategy with IT as a means to that end. A particular attention was given to the Elgin County that is situated in Canada's south western Ontario and houses 46,000 people. This a rich agricultural zone, complemented by a strong and developing industrial base (County of Elgin, 2007). The conclusion of the study is that there is a need to create a targeted development strategy, which can capitalize on Elgin's usually strong inputs. In addition, there is a need for an IT development strategy to support economic progress.

A study that was not restricted to rural specific areas employed US Zip Code level to demonstrate the positive economic outcomes for communities which have installed broadband connections (Lehr, Osorio \& Gillett, 2006). For broadband use in the period of 1998 to 2002, it was found that communities using this technology were more likely to experience growth in employment, number of businesses, and number of businesses in information technology intensive sectors (NBUBRC, 2006). One of the important characteristics of this approach is the fact that it correlates national level economic indicators against places with and without broadband. The authors pointed out that broadband did not act in isolation to enhance productivity, and they urged caution in applying their methodology because of the challenges associated with "disentangling causality in any study of the relationships between infrastructure availability and economic development" (Lehr et al. 2006).

Ramirez and colleagues (Ramirez, Aitkin, Jamieson, \& Richardson, 2004) used a narrative approach to investigate the effects of information technologies on First Nations communities in the remote regions of north western Ontario, Canada. They came to the conclusion that in aboriginal communities in particular the introduction of these technologies had profound consequences for people's everyday lives. For the elders, the changes were sometimes difficult to comprehend, while the young would take them for granted. The challenge was to find that balance which ensured that everyone benefited. Another conclusion is that these technologies offered opportunities to strengthen and protect cultural heritage. Ramirez and colleagues (2004) and the ITU (International Telecommunication Union [ITU], 2006) caution against falling into the trap of attempting to attribute social change exclusively to the adoption and use of broadband. 


\section{Methodology}

Bearing in mind the observation of Ramirez and colleagues (2004) and the ITU (2006) mentioned above, we believe that the narrative approach is the most appropriate to understand broadbandinduced transformations. Quantification and counting numbers are not neglected but combined with narratives and questionnaires.

The total population concerned with the case study is 12,156 . We distributed 280 questionnaires in March 2006 and 158 individuals responded - 81 answered via the paper version of the survey and 77 via the Web-based version. Of all the respondents, 94\% had broadband access at home, while $6 \%$ had dial-up access. The sample used in the study had the following characteristics:

- Fifty-nine percent (59\%) of the respondents where female and $41 \%$ were male.

- The ranging age of the respondents was between 30 and 66 years, and the majority of them were between 30 and 40 years.

- Respondents range from single to married/common law partners. Singles represent $38 \%$ of participants while $38 \%$ are married, $3 \%$ are divorced, $3 \%$ are separated, $1 \%$ are widowed, and $17 \%$ live with partner;

- Four percent (4\%) of the participants have less than high school degree, $8 \%$ completed some high school, $24 \%$ are graduated from high school, $5 \%$ completed some nonuniversity diploma, $9 \%$ completed non-university diploma, $14 \%$ completed some university, $24 \%$ completed university degree, $3 \%$ completed some graduate study, $7 \%$ completed post graduate studies, and $27 \%$ might be students;

- The majority of respondents works in a variety of industries and has a broad range of household incomes. Twenty percent (20\%) have less than $\$ 20000$ a year, 30\% have between $\$ 20000$ and $\$ 40000,27 \%$ have between $\$ 40000$ and $\$ 60000,10 \%$ have between $\$ 60000$ and $\$ 80000$, and finally $13 \%$ have more than $\$ 80000$ a year.

- French is the native language of the $97 \%$ of the respondents. All respondents are quite comfortable using the Internet with an average comfort of four on a scale of one-to-five, and $90 \%$ of them have been doing so for more than two years.

The community had a positive attitude towards the study. The main community contacts for the case study in the Shippagan, Lamèque, Le Goulet, and St Marie-St-Raphael region were Entreprise Péninsule (EP) and Collectivité Ingénieuse de la Péninsule Acadienne (CIPA). The University de Moncton Campus de Shippagan (UMCS) was also very cooperative. University de Moncton, Campus of Shippagan (UMCS) encouraged their employees and students to participate in the survey. UMCS resources were used to develop and print the paper version of both business and household surveys. Students particularly were very enthusiastic to see their community selected for a case study of such importance. Many students who were not resident of the region regretted the fact that they could not participate in the survey. The questions used in the survey are summarized in Appendix.

\section{Findings}

Our findings are grouped in the main themes discovered. Each is discussed below.

\section{Communication and Information}

The respondents use a variety of communication tools. Some of the respondents use the telephone (84\%), e-mail (60\%), cell phones (49\%), instant messaging and chat rooms (49\%) "most days". Modes of communication used less often by respondents include letters and parcels $(83 \%$ of re- 
spondents use this tool at least once a year), audio/video conferencing (29\%), web forums and $\operatorname{logs}(20 \%)$, and voice over Internet telephony $(7 \%)$. In general, use of communication tools has not significantly changed within the last six month among the respondents who answered our survey.

Respondents find information in a variety of locations including those in books and libraries, magazines and newspapers, on television and/or the radio, Internet web browsers, Internet radio/television. Obtaining information from television and the radio, along with Web browsers were the most common trends. In general, the place where respondents find their information has not dramatically changed within the last six months among the respondents who answered our survey.

\section{Leisure Time and Community Involvement}

Respondents spend their leisure time in a variety of ways. On "most days" some respondents will be watching TV (82\%), listening to radio or music (64\%), reading newspapers, magazines or books $(64 \%)$. Fewer will be surfing the Internet for fun (41\%) on a daily basis as well as exercising $(24 \%)$ and downloading or listening to online music (17\%). Except for exercising and playing sports, in which $20 \%$ of respondents said that they increased their participation, leisure activities have not changed that much in the last six months among respondents.

One hundred and thirty two respondents answered the question about Internet use and its impact on family time: $83 \%$ of them feel they spend the same time together as a family since obtaining high-speed access.

Except for visiting family and friends, respondents do not participate greatly in community meetings, events, and activities. For the most part, this has not changed within the last six months.

\section{Mobility and Migration}

There has not been great mobility among respondents' families within the last six months. However, most of the mobility was due to moving out for the pursuit of studies to larger urban areas in the province (e.g. Fredericton, Saint John, and Moncton).

\section{Use of the Internet at Home}

Respondents use the Internet mainly at home and at work, less so at friends' and relatives' homes, and almost none at the Community Access centre. $76 \%$ of respondents use the Internet at home "most days". Fifty-one percent (51\%) of respondents have Internet at work and most have high speed. Forty-one percent (41\%) use the Internet "most days" at work.

Respondents use their high-speed connection at home chiefly for personal use (90\%). Other purposes also include educational ones, paid work, accessing office networks and files, and much more.

Respondents who have high-speed Internet use their connection to search for a variety of information "most days" including hobbies and interests (42\%). Less frequently, respondents also search for information about events in and out of their local area, health concerns, jobs, educational opportunities, travel and tourism information, professional services, government services and real estate values.

Concerning the business related on-line services, the respondents report that they use them in various daily-life needs. High-speed Internet is used more frequently for on-line banking (35\% use it two to three times a week or more). Service New Brunswick, which provides many egovernment services, is used by $48 \%$ of the respondents, once every two weeks or less, $24 \%$ of 
the respondents. The online purchasing represents $24 \%$ of activities and it is done once every two weeks or less.

\section{On-line Purchases}

Since subscribing to high-speed Internet, some respondents have purchased a digital camera (47\%), a web cam (35\%), a new computer (33\%), a USB key (29\%), a photo printer (28\%), a wired or wireless router / switch / hub (22\%), an iPod or an MP3 player (14\%), an LCD computer Screen (12\%), a telephony headset (11\%), a digital video camera (11\%), a scanner (11\%), and a wireless network card $(9 \%)$.

Four respondents indicated that they have a home based business with only one launching a home-based business since subscribing to the high-speed Internet. Two respondents indicated that the geographical reach of their home-based business expanded since subscribing to the broadband Internet. One answered that the reach expanded locally and one to the rest of Canada. Furthermore, two respondents indicated that subscribing to the broadband Internet had a positive financial impact on their home based-business.

\section{Positive Changes}

Respondents of the household survey enumerated the positive changes in their lives. Their answers mainly show the importance of the high speed in performing operations and saving time from moving to the bank, library, travel agency, as well as keeping contact and communicating with relatives and friends. Their answers are summarized in the following list.

- Fast access to the information

- Communication using in addition to the traditional way, email, webcam, videoconferencing

- Trip savings

- $\quad$ Access to online newspapers

- Online banking services

- Online payment

- E-Learning, research for kids school projects, no need to go to the library

- Online purchases

- Entertainment

- Rapidity to do several things [Capability of doing several things at a time]

- Fast downloading of music and documents

- Telephone line is always free

- Working from home.

We must note here, that these positive changes are closely related to the broadband connection, even if they can be compared to those of the Internet use in general. Many of the tasks are very difficult or quite impossible to do with a dial-up connection (IP-telephone, downloading music, working from home, etc.). 


\section{Concerns}

Respondents shared a variety of concerns about the use of the high-speed Internet. The most common concerns include the fraud/confidentiality, the inappropriate content, the bad influences on children, and the security and viruses. Other concerns are related to the costs of the high-speed Internet and its associated equipment and to the addictiveness since it may lead to spending less time with the family and friends. We included in the survey a field where respondents can give their concerns regarding the use of broadband. Here are some examples.

- High cost

- Viruses

- Confidentiality

- Security

- Less time for the family

- Sexual exploitation

- Fear for young people

- Allow spiteful people to commit illegal actions more rapidly

- Full of hatred adult Sites

- Public chats other than MSN, pornography, vulgar words, pedophiles

Some of these concerns remain for a minority of respondents $(2 \%)$ a true obstacle for adopting the High-Speed Internet in a rural region.

\section{Subscribing Challenges}

Before subscribing to the high-speed Internet, $40 \%$ of respondents had difficulty downloading electronic documents, $33 \%$ had difficulty getting video/audio files and $28 \%$ had difficulty playing network games. Fewer respondents indicated difficulty communicating, a lack of specific information and difficulty benefiting from online training, and learning as other challenges.

\section{Transformation and Community Impacts}

From the answers of the participants, the introduction of broadband services to households does not diminish the time that the family spends together as $83 \%$ feel that they spend the same time together as a family. Its introduction allows $33 \%$ of the respondents to perform daily online banking. In addition, we note that deployment of the High-Speed Internet increased the household purchases of electronic devices. Users in households report positive impacts. These impacts are mainly related to the following:

- facilitating the communication with friends;

- making easier education projects;

- improving the quality of life since it allows the payment of bills from home.

In a near future, a proportion of surveyed persons plan to use their high-speed connection to get access to E-learning, to find information about real estate values and purchasing, to do online banking, stock trading/tracking and investment purchases as well as to use Service New Brunswick to pay their bills and have access to its other services. 


\section{Conclusion}

The present study investigated the issue of the social impact of broadband use on the population of the Acadian Peninsula in Canada. In conducting this study, we have perceived the challenges of evaluating the impacts of broadband. In fact, our methodology has been designed to extract context and performance measures from individuals who themselves are incapable of evaluating these impacts. Hence, the limitations are due to the fact that there are subjective and qualitative outcomes which are not easily measured. Tying social impacts to broadband' influence is more consistent if it is clear in which manner the broadband is actually being used in the community, not just available.

The underlying objective of investors, particularly Industry Canada, was to track such social impacts to justify investments made by funding agencies into broadband. They want to better understand the role of broadband technology and what role it can play to enhance the existing business processes and/or to create new opportunities in rural regions. Leveraging the benefits of broadband more fully will require that both individual and organizations clearly understand which broadband technologies offer positive returns on investment. This aspect was not treated by our study and constitutes its main limitation. But, we must underline that this limitation is due to the "time" factor. In fact, tracking changes in use and associated impacts over time, as more and more people get online and become comfortable with the technology and explore what it can do for their business, household or organization, necessitates long-term observations and studies. Then, a possible avenue for refining our study would be to use individual-level data to take a more micro-level view of broadband's impacts on the day-to-day life within and between these individuals and their community and enterprises. Our study, however, could constitute a valuable background to initiate such a targeted and long-term tracking in order to gain a deeper understanding of broadband's impact on rural regions and its relation to growth of different social sectors.

Our study revealed that the deployment of broadband to Shippagan, Lamèque, Le Goulet and Ste Marie St Raphael had a positive effect by making the daily operations easier for $81 \%$ of the population. It improves the access of $75 \%$ of the population to the information that they need. Even if the broadband access is becoming a requirement for the daily life for the majority of respondents, the study reveals that the introduction of broadband does not affect negatively the social relations in rural regions, as clamed by $83 \%$ of the respondents.

It is worthy of noting that the effect of broadband may be more important but it is not apparent. Broadband does not act solely on the socio-economic sphere. On one hand, it is coupled to other kinds of information technology. On the other hand, the huge and general deployment of broadband can help in the development of these technologies. Based on this observation and on experiences from this case study, new research could be initiated by distinguishing between "broadband using" and "broadband adding value". To capture social and economic impacts of broadband on rural communities requires a longer time to collect the pertinent data and to follow the behavioural evolution of both firms and users.

Like the findings of Ramirez and colleagues (2004) with respect to young aboriginal people in remote regions of north western Ontario, none of the respondents in our study can imagine the future without access to broadband. Platis (2004) pointed out that young people move away from their smaller childhood towns to urban places that offer more opportunity. We noticed the same phenomenon in Shippagan area. However, we cannot conclude in our case that the lack of information technology facilities is the main factor behind this transformation, as Platis (2004) stated for his case study. There is not enough evidence for such a conclusion since a significant part of the young population in New-Brunswick leave the whole province to settle up in Alberta, Quebec and especially in Ontario (Statistics Canada, 2001). Almost 14,100 people moved from New 
Brunswick to Ontario in the period of 1996 to 2001. An additional 6,600 moved to Alberta, and 6,200 moved to Quebec. About 6.0\% of New Brunswick's population aged five years and over migrated to other provinces and territories between 1996 and 2001. However, the out-migration rate among young people aged 15 to $29,11.0 \%$ of this population, was nearly double the overall provincial average. Almost 16,400 young people in this age group left the province. Many of these young people were likely searching for work. According to the Labour force survey data, the unemployment rate among youth aged 15 to 24 in New Brunswick averaged 17.7\% between 1996 and 2001, higher than the national average of 14.3\% for this age group (Statistics Canada, 2001). Bearing in mind this context, we reiterate that we cannot conclude that the lack of IT facilities is a major factor causing this migration.

In general, the major message from our case study research is that there is very little evidence of transformation especially at the household level. While there are many examples of new uses and activities as a result of broadband adoption, there are few examples of a change in behaviours and attitudes and relationships and operating norms as a result. This is not surprising given that the technology has only very recently been introduced in many areas of rural New Brunswick (NBUBRC, 2006).

\section{Acknowledgment}

The authors would like to thank Industry Canada for its financial support, "L'Acadie Nouvelle" and Université de Moncton - Shippagan Campus - for their advertising efforts and Yacine Benahmed for his technical support as well as CIPA and Enterprises New Brunswick for their cooperation and fruitful advice.

\section{References}

Bush, G. W. (2004). A new generation of American innovation. Executive Summary and President Bush's presentation of a series of specific measures to inspire a new generation of American innovation on April 26, 2004. Washington D.C.: The White House.

Chang, S., Lee, H., \& Middleton, C. (2004). The deployment of broadband Internet in Australia: Areas for attention and implications from Canada and Korea. Retrieved from www.ryerson.ca/ cmiddlet/pubs/bband_aus.pdf

Cohill, A.M. (2005a). Comnmunity Web Portals and Economic Development. Presentation at the 9th Annual Rural Telecommunications Congress Annual Meeting, Lexington, Kentucky, October 9-12

Cohill, A.M. (2005b). Broadband Policy for Rural Communities. Presentation to the Canadian Government Telecommunications Policy Group, Whitehorse, Yukon Territory, Canada, September 9

Corning, Inc. (2005). Broadband technology overview. Reference WP6321, White Paper.

Comscore Media Metrix (2004). Canada, Demographic profile report. Retrieved March 21, 2007 from http://www.pwgsc.gc.ca/onlineconsultation/text/statistics-e.html

County of Elgin. (2007) ElginConnects 2007.02. Retrieved from http://www.elginconnects.ca/portal/site/elgi/menuitem.080606d1a3cd1407cf2129201891ef9a/

Fransman, M. (2006). Global broadband battles: Why the U.S. and Europe lag while Asia leads. Stanford, CA: Stanford Business Books.

International Telecommunication Union (ITU). (2006). Statistics and analysis: International telecom statistics and analysis. Retrieved April 2, 2007 from http://www.itu.int/osg/spu/statistics/

Lee, H., O'Keefe, R., \& Yun, K. (2003). The growth of broadband and electronic commerce in South Korea: Contributing factors. The Information Society, 19(1), 81-93. 
Lehr, H., Osorio, C., \& Gillett, S. (2005). Measuring broadband's economic impact. Retrieved from http://cfp.mit.edu/groups/broadband/docs/2005/MeasuringBB_EconImpact.pdf

Marlin, A., \& Bruce, D. (2006). Transforming a rural society: Impacts of broadband adoption and use in rural New Brunswick institutions. Retrieved from http://www.mta.ca/rstp/Amanda_ICSpaper.doc

New Brunswick Universities Broadband Research Consortium. (2006). Transforming a rural society: Impact of broadband adoption in rural New Brunswick. Report edited for Industry Canada.

Organisation for Economic Co-Operation and Development. (2006). OECD broadband statistics, June 2006. Retrieved March 27, 2007 from http://www.oecd.org/dataoecd/50/49/37530046.xls

Platis, A. (2004). 2004 rural youth survey reveals shift in teen preferences; New windows of opportunity for rural telecom carriers. 2004 Rural Youth Telecommunications Survey. NTCA; Foundation for Rural Service.

Ramirez, R., Aitkin, H., Jamieson, R., \& Richardson, D. (2004). Harnessing ICTs: A Canadian First Nations experience. University of Guelph. Retrieved from http://knet.ca/documents/INTRO-KNet-ver.pdf

Ruiz, A. (2004). Broadband Internet and rural America: The role of government in providing un-served communities with advanced telecommunications services. Santa Barbara: University of California, UCDC Washington Program.

Selouani, S.-A., Hamam, H., \& Benahmed, Y. (2007). Broadband technology in the Acadian Peninsula: Report based on a case study. IEEE Canadian Review, 54, 8-12.

Statistics Canada. (2001). New Brunswick: Heavy losses in migration to Ontario. Retrieved from http://www12.statcan.ca/english/census01/products/analytic/companion/mob/nb.cfm

Statistics Canada. (2006). Standard geographical classification (SGC) volume II. Based on 2001 census, updated in 2006. Retrieved from http://www.statcan.ca/bsolc/english/bsolc?catno=12-572-X

Strategic Networks Group (SNG), EKOS, \& Phoenix Strategic Perspectives Inc. (2004). Socio-economic impact study of FedNor broadband and ICT investments in Timmins and Cochrane District, Ontario. Report Retrieved from http://sngroup.com/documents/papers.htm

US Broadband Penetration Nears 70\% Among Active Internet Users - US-Canadian Broadband Gap Narrows - April 2006 Bandwidth Report. (2006). Retrieved March 27, 2007 from http://www.websiteoptimization.com/bw/0604/

Veenhof, B., Neogi, P., \& Van Tol, B. (2003). High-speed on the Information Highway: Broadband in Canada, Industry Canada.

Zamaria, C., Caron, A. H., \& Fletcher, F. (2005). Canada online! A comparative analysis of Internet users and non-users in Canada and the world: Behaviour, attitudes and trends 2004. Toronto: Canadian Internet Project. 


\section{Appendix}

In general, the questions set in the survey are summarised as follows.

- General information

- In general, the topics related the questions set in the survey are listed below.

- Methods used to access to the information

- Methods used to communicate with friends, relative and people in general

- How spending leisure time

- How participating in community events

- Information on family members who are away

- Information about the participant and family members

- Personal information of the participant and his/her family members, such as age, education level and so on.

- Other information including the income, comfort in using Internet, language spoken at home, etc.

- Information related to the use of the Internet

- Information related to the use of Broadband technology

- Changes noticed when moving from Dial Up to Broadband

- Activities performed through the Broadband Internet

- Business-related activities

- Comments of the participant such as positive changes, concerns, and challenges faced with Broadband Technology 


\section{Biographies}

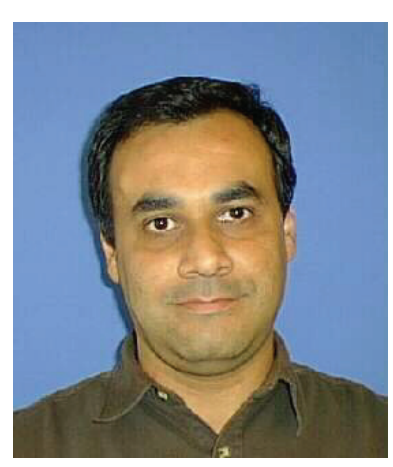

Dr. Sid-Ahmed Selouani is currently Associate Professor and responsible of the Human-Machine Interaction Lab. at Universite de Moncton, Campus of Shippagan, Canada. He is also an Invited Professor at INRS-Énergie-Matériaux-Télécommunications of Quebec, Canada. His main areas of research include new models in E-Commerce, mobile communications, ubiquitous systems and assistive technologies by speech-enabled solutions.

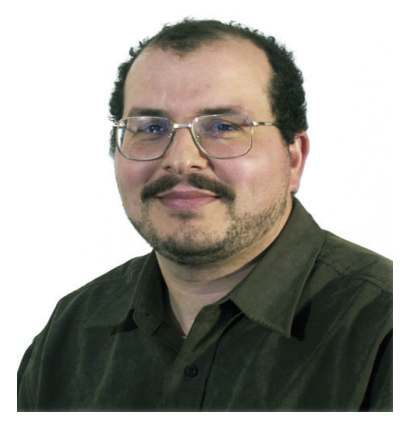

Dr. Habib Hamam is a Full Professor of Telecommunications in the Dept of Electrical Engineering and a Canada Research Chair in "Optics in Information and Communication Technologies" at Université de Moncton, Canada, and a Director of the Research Center of the Canadian University of Dubai. His interests in research include optical and wireless telecommunications, diffraction, fiber components and ELearning. 